\title{
RENCANA PENGEMBANGAN KAMPUNG CINA DI KOTA WISATA CIBUBUR UNTUK MENINGKATKAN DAYA TARIK PENGUNJUNG
}

\author{
Defita Andina Kandi ${ }^{1}$, Priyendiswara A. ${ }^{2)}$, Liong Ju Tjung ${ }^{3)}$
}

\begin{abstract}
1)Program Studi S1 PWK, Fakultas Teknik, Universitas Tarumanagara, defitaandinakandi@gmail.com
2)Program Studi S1 PWK, Fakultas Teknik, Universitas Tarumanagara, priyendiswaraa@ft.untar.ac.id

3)Program Studi S1 PWK, Fakultas Teknik, Universitas Tarumanagara, jt.liong@pps.untar.ac.id
\end{abstract}

\begin{abstract}
Abstrak
Kampung Wisata Ciangsana atau yang lebih dikenal Kampung Cina yang berlokasi di Kabupaten Bogor, Jawa Barat, telah berdiri sejak tahun 2002. Wisata ini ramai dikunjungi oleh wisatawan baik dari sekitar Bogor maupun Jakarta, Depok, Tangerang, Bekasi dan daerah-daerah lainnya. Wisata yang memiliki luas 0,8 hektar ini memiliki target pengunjung masyarakat ekonomi kelas menengah dan menengah bawah. Kondisi wisata Kampung Cina saat ini bila dilihat dari siklus hidup produk berada di posisi menurun dan apabila dibiarkan akan mengakibatkan kondisi Kampung Cina yang tidak terawat dan tidak menarik serta menurunnya kualitas pelayanan. Oleh karena itu, pada penelitian ini akan dibuat rencana pengembangan dengan cara mengetahui kelayakan investasi untuk membuat rencana pengembangan di Kampung Cina kedepannya dengan menggunakan pendekatan kualitatif dan kuantitatif serta melakukan analisis-analisis yang berkaitan dengan pengembangan wisata, seperti analisis lokasi dan tapak, analisis objek studi sejenis, analisis pasar, analisis kebutuhan ruang dan analisis kelayakan investasi. Analisis yang dilakukan menggunakan alat analisis yaitu deskriptif, SWOT, benchmarking, crosstabulation, standar kebutuhan ruang dan discounted cash flow. Penulisan ini hanya menampilkan analisis kelayakan investasi untuk dijadikan salah satu acuan pembuatan denah rencana tapak.
\end{abstract}

Kata Kunci: Kampung Cina; Studi Kelayakan; Wisata

\begin{abstract}
The Ciangsana Tourism Village or better known as Chinese Village, located in Bogor Regency, West Java, has been established since 2002. The tour is crowded with tourists both from around Bogor and Jakarta, Depok, Tangerang, Bekasi and other areas. Tourism that has an area of 0.8 hectares has a target audience of middle and lower middle class economic people. The current tourism conditions of Chinese villages when viewed from the product life cycle are in a decline position and if left unchecked will result in unkempt and unattractive Chinese Village conditions and declining quality of service. Therefore, in this study a development plan will be made by knowing the feasibility of investing in making future development plans in Chinese villages using qualitative and quantitative approaches and conducting analyzes related to tourism development, such as site analysis and site analysis, object analysis similar, market analysis, space requirements analysis and investment feasibility analysis. The analysis was carried out using analytical tools namely descriptive, SWOT, benchmarking, crosstabulation, standard space requirements and discounted cash flow. This writing only shows the investment feasibility analysis to be used as a reference for making site plans.
\end{abstract}

Keywords: Chinese Village; Feasibility Study; Tourism

\section{PENDAHULUAN}

Di Kabupaten Bogor tepatnya di Kecamatan Gunungputri terdapat sebuah Kampung Wisata yang dikenal sebagai Kampung Cina yang terletak di dalam perumahan Kota Wisata Cibubur dengan luas 15,5 hektar. Kampung Wisata ini sudah beroperasi sejak Oktober 2002 kawasan ini terbagi menjadi 4 titik destinasi wisata yaitu Kampung Indonesia, Kampung Jepang, Kampung Amerika dan Kampung Cina, selain itu Kampung Wisata juga dilengkapi dengan area bermain 
yaitu Fantasy Island, Kampung Wisata sendiri berisikan kios-kios yang mayoritas dimiliki oleh individu. Tujuan awal didirikannya Kampung Wisata ini adalah sebagai fasilitas bagi penghuni yang tinggal di perumahan Kota Wisata, namun lama-kelamaan Kampung Wisata tidak hanya dikunjungi oleh orang-orang yang tinggal di perumahan Kota Wisata saja tetapi juga dari orangorang di luar perumahan Kota Wisata.

Seiring berjalannya waktu kondisinya saat ini Kampung Indonesia, Kampung Amerika dan Kampung Jepang sudah tidak lagi berfungsi sebagai tempat wisata sehingga pihak pengelola membongkar tiga Kampung Wisata tersebut diikuti dengan pembongkaran area bermain Fantasy Island dan hanya tersisa Kampung Cina yang rencananya akan dilakukan pengembangan kembali oleh pihak pengelola. Pembongkaran yang sudah dilakukan sebelumnya oleh pihak pengelola yaitu dengan melakukan strategi buyback kios-kios yang dimiliki oleh individu. Saat ini bangunan yang masih berdiri di Kampung Wisata hanyalah Kampung Cina memiliki luas 0,8 hektar yang merupakan Kampung Wisata yang lebih diminati oleh wisatawan dibandingkan dengan kampung wisata lainnya. Kampung Cina sendiri nantinya merupakan bagian dari rencana pengembangan CBD Kota Wisata dengan luas 39,6 hektar. Menurut pengelola dari Kampung Cina sebenarnya kawasan ini memiliki potensi yang sangat baik jika dikembangkan, sehingga perlu adanya perencanaan dan pengembangan fasilitas dan kondisi bangunan yang matang agar kegiatan wisata yang ada bisa terus berjalan dan memberikan pendapatan.

Berdasarkan data pengelola dari tahun 2002 sampai dengan 2018 jumlah pengunjung tertinggi adalah pada tahun 2004 jumlah pengunjung Kampung Cina mencapai 2.796.146 pengujung, sedangkan jumlah pengunjung terendah berada pada tahun 2017 yaitu sebanyak 131.033 pengunjung. Sehingga lama-kelamaan jumlah pengunjung Kampung Cina mulai turun setiap tahunnya, dengan dibongkarnya area bermain anak jumlah pengunjung pun semakin menurun.

Tabel 1. Jumlah Pengunjung Kampung Cina Tahun 2002- 2018

\begin{tabular}{cccc}
\hline No. & Tahun & Jumlah Pengunjung (Jiwa) & Peningkatan (\%) \\
\hline 1. & 2002 & $414.196^{*}$ & - \\
\hline 2. & 2003 & 2.147 .755 & $80,7 \%$ \\
\hline 3. & 2004 & 2.796 .146 & $23,2 \%$ \\
\hline 4. & 2005 & 2.017 .182 & $-38,6 \%$ \\
\hline 5. & 2006 & 1.506 .047 & $-33,9 \%$ \\
\hline 6. & 2007 & 1.254 .756 & $-20,02 \%$ \\
\hline 7. & 2008 & 1.171 .920 & $-7,06 \%$ \\
\hline 8. & 2009 & 1.447 .783 & $19,05 \%$ \\
\hline 9. & 2010 & 1.253 .366 & $-15,51 \%$ \\
\hline 10. & 2011 & 1.088 .373 & $-15,16 \%$ \\
\hline 11. & 2012 & 798.773 & $-36,26 \%$ \\
\hline 12. & 2013 & 612.549 & $-30,40 \%$ \\
\hline 13. & 2014 & 275.946 & $-121,9 \%$ \\
\hline 14. & 2015 & 189.040 & $-45,97 \%$ \\
\hline 15. & 2016 & 221.240 & $-68,84 \%$ \\
\hline 16. & 2017 & 131.033 & $7 \%$ \\
\hline 17. & 2018 & 141.562 & \\
\hline
\end{tabular}

Keterangan: ${ }^{*}$ Oktober - Desember 2002

Sumber: Pengelola Kampung Cina, 2002 - 2018

Alasan penulis melakukan penelitian pada Kampung Cina dikarenakan terjadinya penurunan jumlah pengunjung pada Kampung Cina, Kampung Cina sebenarnya memiliki potensi yang sangat baik sehingga penulis ingin melakukan pengembangan pada Kampung Cina yang berfokus pada analisis kelayakan investasi dengan masyarakat kelas menengah sebagai target marketnya. 


\section{KAJIAN LITERATUR}

Turisme atau yang lebih dikenal dengan pariwisata menurut World Tourism Organization (WTO) pariwisata adalah kegiatan berpergian yang dilakukan secara individu atau berkelompok ke suatu tempat dalam waktu yang tidak lama dengan tujuan untuk kesenangan, bisnis dan tujuan laninnya. Sedangkan menurut Undang-Undang No. 10 Tahun 2009 tentang Kepariwisataan, pariwisata didefinisikan sebagai kegiatan yang dilakukan untuk menikmati objek dan daya tarik wisata, kegiatan wisata yang didukung dengan berbagai fasilitas yang disediakan oleh masyarakat, pengusaha, pemerintah dan pemerintah daerah.

Dalam melakukan pengembangan pariwisata (Swarbrooke, 1996) terdapat beberapa jenis pengembangan, yaitu:

1) Keseluruhan dengan tujuan baru, membangun atraksi di situs yang tadinya tidak digunakan sebagai atraksi.

2) Tujuan baru, membangun atraksi pada situs yang sebelumnya telah digunakan sebagai atraksi.

3) Pengembangan baru secara keseluruhan pada keberadaan atraksi yang dibangun untuk menarik pengunjung lebih banyak dan untuk membuat atraksi tersebut dapat mencapai pasar yang lebih luas, dengan meraih pangsa pasar yang baru.

4) Pengembangan baru pada keberadaan atraksi yang bertujuan untuk meningkatkan fasilitas pengunjung atau mengantisipasi meningkatnya pengeluaran sekunder oleh pengunjung.

5) Penciptaan kegiatan-kegiatan baru atau tahapan dari kegiatan yang berpindah dari satu tempat ke tempat lain dimana kegiatan tersebut memerlukan modifikasi bangunan dan struktur.

Sedangkan keberhasilan dari pengembangan meliputi berbagai kelayakan (Suwantoro, 1997), seperti kelayakan finansial, kelayakan sosial ekonomi regional, layak teknis dan layak lingkungan.

Kelayakan finansial suatu ukuran yang menyeluruh yang dapat menggambarkan tingkat kelayakan proyek. Dalam analisis kelayakan finansial proyek tujuan analisis finansial adalah efesiensi finansial dari modal yang ditanam dilihat dari sudut individu atau investor. Pada analisis kelayakan finansial terdapat komponen yang diperhitungkan dan sangat berpengaruh ialah komponen finansial yang berpengaruh pada "private return" atau tingkat pengembalian bagi investor (LPKM-ITB, 1997). Analisis kelayakan finansial dilakukan untuk mengetahui tingkat kelayakan suatu proyek.

\section{METODE}

\section{Lokasi dan Waktu Penelitian}

Penelitian ini dilakukan di Kampung Cina Cibubur, Desa Ciangsana, Kecamatan Gunungputri seluas 0,8 hektar.

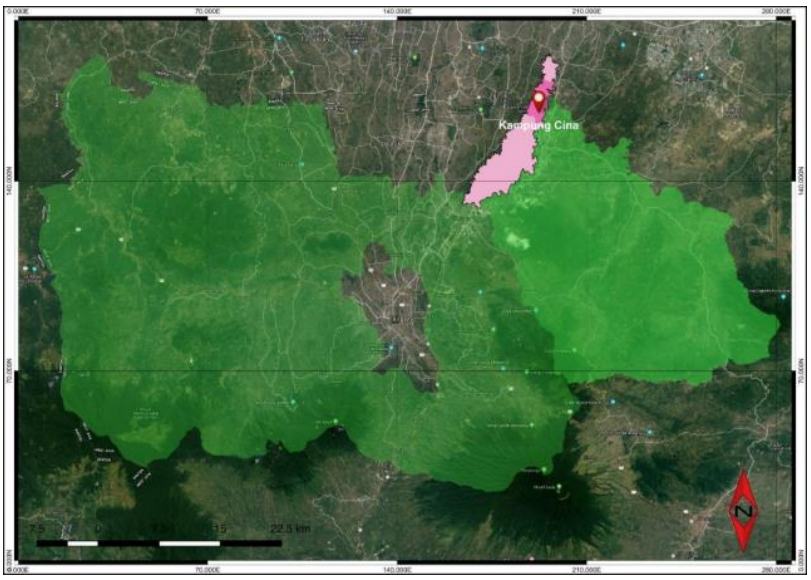

Gambar 1. Lokasi Penelitian

Sumber: Penulis, 2018 


\section{Metode Pengumpulan Data}

Data primer yang dikumpulkan berupa kondisi fisik Kampung Cina dan objek studi sejenis, wawancara dengan pihak pengelola dan kuesioner yang disebarkan kepada pengunjung dan pemilik kios.

1) Populasi

Total pengunjung teramai adalah 2.796.146 pengunjung pada tahun 2004 .

2) Sampel

Penentuan sampel menggunakan rumus slovin, yaitu:

\section{Keterangan:}

$$
\mathrm{n}=\frac{\mathrm{N}}{1+\mathrm{N} \cdot \mathrm{e}^{2}}
$$

n : Jumlah Sampel (responden)

$\mathrm{N}$ : Jumlah Populasi (orang)

e : Persentase kelonggaran ketidaktelitian karena kesalahan

pengambilan sampel yang masih dapat ditolerir

Jadi, perhitungan sampel untuk penyebaran kuesioner adalah:

$$
\mathrm{n}=\frac{\mathrm{N}}{1+\mathrm{N} \cdot \mathrm{e}^{2}}=\frac{2.796 .146}{1+2.796 .146 .0,1^{2}}
$$

$\mathrm{n}=99,99$ responden $\approx 100$ responden yang disebarkan kepada pengunjung

3. Kuesioner juga disebarkan kepada pemilik kios yang ada di Kampung Cina mengingat sebagian kios yang ada di Kampung Cina adalah milik individu sebanyak 142 kios.

Data sekunder yang dikumpulkan berupa letak geografis serta dokumen terkait dari internet yang dapat dipertanggungjawabkan.

\section{Alat Analisis}

Alat analisis yang digunakan berupa:

1) Deskriptif untuk mendeskripsikan kondisi secara kualitatif.

2) SWOT (Strenght, Weakness, Opportunity, Threats) untuk membandingkan antara faktor eksternal dan faktor internal sehingga didapat strategi yang harus dilakukan.

3) Benchmarking untuk melakukan perbandingan kawasan atau objek studi lain yang memiliki kondisi dan konsep yang sama dengan objek studi.

4) Crosstabulation digunakan untuk melihat terdapat hubungan antara dua variable atau lebih.

5) Standar Kebutuhan Ruang digunakan untuk menentukan besaran ruang yang akan dikembangan di dalam objek studi berdasarkan standar dan objek studi sejenis.

6) Discounted Cash Flow

a) Net Present Value (NPV)

Metode yang dikenal dengan Present Worth ini membandingkan semua biaya pembangunan dengan acuan yang ada, bertujuan agar dapat dibandingkan antara satu dengan yang lainnya. Acuan yang dipergunakan adalah besaran netto saat ini (Net Present Value) sebagai selisih antara Present Value dari komponen manfaat dan Present Value dari komponen biaya. Dengan rumus sebagai berikut:

Rumus:

$$
\mathrm{NPV}=\frac{C o+C t}{(1+r)^{t}}
$$

Keterangan:

Co : Investasi awal

$\mathrm{Ct} \quad$ : Besaran total dari komponen biaya pada tahun ke-t

$r \quad$ : Tingkat bunga yang diperhitungkan atau diskonto

t : Waktu investasi

Untuk mengetahui apakah rencana suatu investasi tersebut layak atau tidak, diperlukan suatu ukuran atau kriteria tertentu dalam metode NPV, yaitu: 
(1) NPV > 0, artinya investasi akan menguntungkan/layak

(2) NPV $<0$, artinya investasi tidak menguntungkan/tidak layak

b) Internal Rate of Return (IRR)

IRR atau Internal Rate of Return adalah besaran yang menunjukkan harga discount rate pada saat besaran NPV $=0$. Dalam hal ini IRR dapat dianggap sebagai tingkat keuntungan atas investasi bersih dalam suatu proyek, dirumuskan sebagai berikut:

Rumus:

$$
\mathrm{IRR}=i_{1}+\frac{\mathrm{NPV}_{1}}{\left(\mathrm{NPV}_{1}-\mathrm{NPV}_{2}\right)}\left(i_{2}-i_{1}\right)
$$

Keterangan:

$\mathrm{i}_{1} \quad$ : Tingkat diskonto yang menghasilkan NPV+

$\mathrm{i}_{2} \quad$ : Tingkat diskonto yang menghasilkan NPV-

$\mathrm{NPV}_{1} \quad$ : Net Present Value bernilai positif

$\mathrm{NPV}_{2} \quad$ : Net Present Value bernilai negatif

Untuk mengetahui apakah suatu rencana investasi layak atau tidak setelah melalui metode ini adalah:

(1) IRR $\geq$ Suku bunga maka suatu proyek dikatakan layak

(2) IRR $\leq$ Suku bunga maka suatu proyek dinyatakan tidak layak

c) Payback Period

Payback Period adalah jangka waktu yang diperlukan untuk mengembalikan modal suatu investasi, dihitung dari aliran kas besih. Indeks payback period, yaitu menggambarkan lamanya waktu yang dibutuhkan agar total inflow sama dengan total outflow. Kriteria kelayakan yaitu:

(1) Proyek dikategorikan sebagai proyek yang layak jika masa pemulihan modal lebih pendek dari pada usia ekonomis proyek.

(2) Proyek dikategorikan sebagai proyek yang tidak layak jika masa pemulihan modal lebih lama dari pada usia ekonomis proyek.

\section{Metode Analisis}

Metode analisis ini bertujuan untuk mencapai tujuan penelitian, berikut ini adalah analisis dan metode yang digunakan:

1) Analisis Lokasi \& Tapak

Pada analisis ini bertujuan untuk membahas lokasi dan tapak dari Kampung Cina dari segi lokasi dan tapak, sehingga dapat mengetahui potensi dan permasalah utama dari luar (eksternal) dan dalam (internal) kawasan. Pada pembahasan luar kawasan (eksternal) membahas mengenai aksesibilitas, moda transportasi, keterdekatan dengan fasilitas, peran kawasan terhadap sekitar terkait kabupaten dan atau kota serta kondisi Kampung Cina. Sedangkan pada pembahasan dalam kawasan (internal) membahas mengenai zoning dari kawasan tersebut terkait pemanfaatan lahan. Setelah dilakukan analisis ini maka dirumuskan dalam potensi dan permasalahan utama dengan menggunakan metode analisis deskriptif dan SWOT.

2) Analisis Objek Studi Sejenis

Analisis ini dilakukan untuk menemukan tempat-tempat wisata sejenis dengan Kampung Cina. Kemudian mencari, menelaah dan menganlisis informasi terkait objek studi sejenis untuk dapat menemukan karakteristik dari objek studi sejenis tersebut yang berguna bagi analisis lainnya untuk membantu menjadi indikator penentu keputusan karena dianggap sebagai pendahulu sehingga dapat dicontoh atau dijadikan sebagai pelajaran bagi objek studi kedepannya. Analisis ini juga bertujuan untuk mengetahui seberapa kemiripan konsep dan 
kondisi objek studi dengan objek studi sejenis. Metode ini merupakan metode analisis deskriptif dengan menggunakan alat analisis benchmarking.

3) Analisis Pasar

Analisis pasar yang dilakukan adalah analisis pasar mikro, yang akan membahas lebih berfokus langsung pada objek studi. Di dalam analisis pasar terdapat 2 (dua) analisis yakni analisis persepsi stakeholder dan analisis penentuan harga. Dari analisis persepsi stakeholder akan diketahui hal-hal apa saja yang dibutuhkan dalam pengembangan kawasan berdasarkan pandangan dari pengunjung, pengelola dan pemilik. Untuk analisis persepsi pengunjung menggunakan metode deskriptif dan SPSS, sedangkan analisis penentuan harga dilakukan untuk mengetahui perkiraan harga untuk menghasilkan pemasukan. Untuk analisis penentuan harga menggunakan metode deskriptif dan scoring.

4) Analisis Kebutuhan Ruang

Analisis kebutuhan ruang dilakukan untuk mengetahui apa saja ruang-ruang yang dibutuhkan di lokasi objek studi yang didasari oleh objek studi sejenis dan pengunjung dari objek studi. analisis kebutuhan ruang ini menggunakan metode perhitungan kebutuhan ruang. Dari analisis ini akan didapatkan mengenai komposisi yang dibutuhkan untuk masing-masing ruang berdasarkan jumlah pengunjung dan objek studi sejenis.

5) Analisis Investasi

Analisis investasi dilakukan dengan menggunakan metode analisis discounted cash flow untuk mengetahui nilai investasi proyek beserta pengembaliannya. Setelah mendapatkan hasil dari analisis-analisis sebelumnya maka akan dihitung apakah pengembangan yang dilakukan dapat menguntungkan bagi pengembang atau tidak. Analisis investasi merupakan parameter apakah seluruh rangkaian pengembangan yang akan dilakukan dapat dianggap layak secara finansial bagi pemilik maupun bagi masyarakat yang ada di Kampung Cina tersebut.

\section{DISKUSI DAN HASIL}

Pada bagian ini menjelaskan setiap analisis penelitian secara rinci. Setiap informasi yang diberikan didukung dengan data-data seperti tabel dan gambar.

\section{Gambaran Umum}

Kampung Wisata lebih dikenal dengan nama Kampung Cina, dulu terdiri dari 4 kampung wisata yakni Kampung Cina yang pertama kali dibangun dan ikuti oleh kampung-kampung wisata lainnya, seperti Kampung Indonesia, Kampung Amerika dan Kampung Jepang. Tujuan didirikannya Kampung Cina ini adalah sebagai fasilitas rekreasi yang diperuntukkan untuk penghuni perumahan Kota Wisata. Seiring berjalannya waktu yang berkunjung ke Kampung Wisata pun tidak hanya penghuni perumahan Kota Wisata tetapi dari luar, bahkan beberapa pengunjung datang dari luar Jakarta ataupun dari luar Pulau Jawa sehingga jumlah pengunjungnya pun sempat mengalami kejayaan pada masanya yaitu tahun 2004. Kampung Cina selain sebagai tempat rekreasi juga sebagai tempat perdagangan yang khusus menjual pernak-pernik Cina.

Pengelola

Pemilik Lahan

Luas

Tahun Operasiona

\section{: PT. Mekanusa Cipta \\ : Sinar Mas Land}

: 0,8 hektar

$: 2002$

Waktu operasional Kampung Cina yaitu dibuka setiap hari dari senin sampai dengan minggu pukul 09.00-16.00 WIB. Harga tiket masuk untuk ke Kampung Cina tidak dikenakan biaya.

Lokasi Kampung Cina, terletak di dalam perumahan Kota Wisata Cibubur, di Jalan Boulevard Kota Wisata, Desa Ciangsana, Kecamatan Gunungputri, Kabupaten Bogor, Jawa Barat. Saat ini Kampung Wisata hanya tinggal memiliki 1 destinasi wisata, yakni Kampung Cina dengan luas 0,8 hektar yang berada di dalam area kawasan CBD Kota Wisata, yang dapat dijangkau dengan 
menggunakan kendaraan pribadi (mobil/motor) maupun kendaraan umum. Dari Jabodetabek juga dapat ditempuh melalui Tol Jagorawi (exit Tol Cibubur) sehingga mempermudah bagi pengunjung yang berasal dari luar Jakarta.

\section{Analisis Lokasi dan Tapak}

Untuk menuju Kampung Cina terdapat jalan yang menghubungkan langsung dengan jalan utama yakni Jl. Raya Kota Wisata yang terhubung langsung dengan Jl. Alternatif Cibubur yang merupakan jalan alternatif yang dapat menghubungkan Jakarta dengan Cianjur/Bandung. Secara aksesibilitasnya lokasi dari Kampung Cina ini cukup baik, namun untuk sampai di Kampung Cina pengunjung perlu menggunakan ojek sekitar $\pm 3,6 \mathrm{~km}$ apabila menggunakan kendaraan umum. Jika menggunakan kendaraan pribadi pengunjung dapat langsung menuju Kampung Cina. Selain itu apabila ditempuh melalui Jl. Canadian Broadway dapat terhubung dengan Jl. Raya Narogong yang merupakan jalan yang dapat menghubungan Bekasi dengan Bogor. Bila melalui Jl. Raya Narogong secara aksesibilitasnya lebih dekat namun pengunjung juga perlu menggunakan ojek sekitar $\pm 2,2 \mathrm{~km}$ untuk sampai ke lokasi Kampung Cina akan tetapi armada untuk kendaraan umum yang melewati jalan ini sangat jarang sekali. Berikut adalah gambaran rute ke Kampung Cina.

Tabel 2. Gambaran Rute Menuju Kampung Cina

\begin{tabular}{ccccccc}
\hline No. & $\begin{array}{c}\text { Nama } \\
\text { Daerah }\end{array}$ & $\begin{array}{c}\text { Daerah } \\
\text { Tujuan }\end{array}$ & $\begin{array}{c}\text { Jarak } \\
(\mathbf{k m})\end{array}$ & $\begin{array}{c}\text { Waktu } \\
\text { (Jam - Menit) }\end{array}$ & Keterangan & Angkutan Umum \\
\hline 1. & Jakarta & Kampung Cina & 37 & 1 jam 8 menit & Via Tol & Ada \\
\hline 2. & Bekasi & Kampung Cina & 19 & 58 menit & Via Non Tol & Ada \\
\hline 3. & Depok & Kampung Cina & 28 & $\begin{array}{c}1 \text { jam } 13 \\
\text { menit }\end{array}$ & Via Tol & Tidak Ada \\
\hline 4. & Depok & Kampung Cina & 27 & $\begin{array}{c}1 \text { jam } 19 \\
\text { menit }\end{array}$ & Via Non Tol & Ada \\
\hline 5. & Bogor & Kampung Cina & 44 & $\begin{array}{c}1 \text { jam } 10 \\
\text { menit }\end{array}$ & Via Tol & Ada \\
\hline 6. & Bogor & Kampung Cina & 39 & $\begin{array}{c}1 \text { jam } 18 \\
\text { menit }\end{array}$ & Via Non Tol & $\begin{array}{c}\text { Ada, melalui Stasiun } \\
\text { Pondok Cina }\end{array}$ \\
\hline 7. & Cianjur & Kampung Cina & 82 & $\begin{array}{c}2 \text { jam } 41 \\
\text { menit }\end{array}$ & Via Non Tol & $\begin{array}{c}\text { Ada, melalui Terminal } \\
\text { Cileungsi }\end{array}$ \\
\hline 8. & Cianjur & Kampung Cina & 95 & $\begin{array}{c}2 \text { jam } 56 \\
\text { menit }\end{array}$ & Via Tol & Ada \\
\hline
\end{tabular}

Sumber: Penulis, 2019

Berdasarkan RTRW Kabupaten Bogor Tahun 2016 - 2030 kawasan ini terdapat rencana jalan tol yaitu Tol Cimanggis - Cibitung yang saat ini sedang dalam pembangunan dan terdapat akses pintu tol langsung dari dalam kawasan Kota Wisata yang jaraknya \pm 100 meter dari pintu gerbang utama Kota Wisata. Selain sedang berjalannya pembangunan jalan tol juga sedang berjalan pembangunan stasiun LRT berjarak $\pm 20 \mathrm{~km}$ ke stasiun LRT Cibubur dengan waktu tempuh 30 menit dan $\pm 7 \mathrm{~km}$ ke Terminal Cileungsi dengan waktu tempuh 15 menit pada jam normal atau bukan pada jam sibuk (pick hour and rush hour), sehingga nantinya dapat menambah value wisata dengan adanya kemudahan akses.

Sedangkan dari segi fasilitas, dapat dikatakan bahwa di Kampung Cina sudah memiliki beberapa fasilitas yang harus disediakan oleh tempat wisata namun beberapa fasilitas dapat dikatakan kondisinya kurang memadai dan tidak baik, sedangkan untuk utilitas dapat dikatakan sudah cukup baik namun tetap diperlukan peningkatan kualitas agar seluruh utilitas dalam kondisi baik dan kegiatan wisata di Kampung Cina dapat berjalan dengan baik. 


\section{SWOT}

Dari analisis lokasi dan tapak maka digabungkan menjadi bentuk SWOT diantaranya:

Tabel 3. SWOT

\begin{tabular}{ll}
\hline \multicolumn{1}{c}{ Strength } & \multicolumn{1}{c}{ Weakness } \\
\hline $\begin{array}{l}\text { Tarif masuk Kampung Cina cenderung murah/gratis } \\
\text { sebagai salah satu daya tarik wisata Kampung Cina. }\end{array}$ & Kurangnya wahana wisata \\
\hline Memiliki bentuk bangunan yang unik & Kurangnya fasilitas umum \\
\hline $\begin{array}{l}\text { Merupakan satu-satunya wisata buatan manusia } \\
\text { berbasis budaya yang dapat dicapai dari JaDeTaBek }\end{array}$ & Pemasaran/promosi tidak maksimal \\
\hline $\begin{array}{l}\text { Berada di dalam kawasan perumahan dimana jaringan } \\
\text { jalan di dalam kawasannya sudah sangat baik }\end{array}$ & \\
\hline \multicolumn{1}{c}{ Opportunity } & \begin{tabular}{l} 
Threats \\
\hline Sektor pariwisata semakin diminati dan berkembang
\end{tabular} \\
$\begin{array}{ll}\text { Testimoni atau opini pengunjung terhadap Kampung moda transportasi menuju lokasi } \\
\text { Cina }\end{array}$ & $\begin{array}{l}\text { Persaingan antar objek wisata di sekitar } \\
\text { objek studi dalam radius 15 km }\end{array}$ \\
\hline
\end{tabular}

Sumber: Penulis, 2019

Dari SWOT yang ada maka dibentuk strategi-strategi untuk mengatasi kekurangan yang ada di Kampung Cina, diantaranya terdapat pada tabel di bawah ini:

Tabel 4. Strategi dari Hasil SWOT

\begin{tabular}{|c|c|}
\hline $\mathbf{S}-\mathbf{O}$ & $\mathbf{w}-\mathbf{0}$ \\
\hline $\begin{array}{l}\text { Membuat rencana pengembangan dengan lebih menonjolkan } \\
\text { keunikan bentuk bangunan yang dimiliki }\end{array}$ & $\begin{array}{l}\text { Memanfaatkan opini pengunjung } \\
\text { terhadap daya tarik Kampung Cina } \\
\text { sebagai media untuk promosi }\end{array}$ \\
\hline \multirow[t]{2}{*}{$\begin{array}{l}\text { Menjadikan daya tarik yang dimiliki Kampung Cina sebagai nilai } \\
\text { tambah dan nilai jual yang unik dalam mengembangkan } \\
\text { kawasan }\end{array}$} & Memperbanyak fasilitas umum \\
\hline & $\begin{array}{l}\text { Memperbanyak titik-titik untuk } \\
\text { area wisata (wahana wisata) }\end{array}$ \\
\hline $\mathbf{S}-\mathbf{T}$ & $\mathbf{W}-\mathbf{T}$ \\
\hline $\begin{array}{l}\text { Membangun infrastruktur yang mendukung aksesibilitas } \\
\text { menuju Kampung Cina sehingga tetap diminati dan dapat } \\
\text { bersaing dengan wisata lain dari segi kemudahan pencapaian }\end{array}$ & 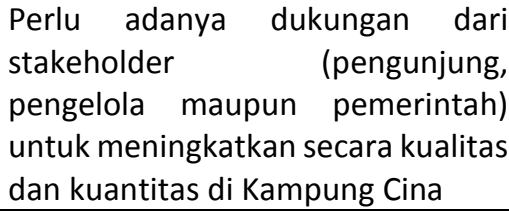 \\
\hline \multicolumn{2}{|l|}{$\begin{array}{l}\text { Mengembangkan potensi yang ada sehingga mampu menarik } \\
\text { pengunjung untuk datang ke Kampung Cina }\end{array}$} \\
\hline \multicolumn{2}{|l|}{$\begin{array}{l}\text { Disediakannya transportasi antar jemput dari gerbang kawasan } \\
\text { perumahan Kota Wisata menuju Kampung Cina }\end{array}$} \\
\hline $\begin{array}{l}\text { Menetapkan harga tiket masuk sebagai biaya retribusi } \\
\text { kebersihan dan perawatan kawasan Kampung Cina }\end{array}$ & \\
\hline
\end{tabular}

\section{Analisis Objek Studi Sejenis}

Dari analisis objek studi sejenis ini didapatkan kesimpulan adalah pada masing-masing benchmark yang sudah ditentukan akan diambil kelebihannya yang dapat dicontoh oleh objek studi. Chinatown Bandung akan menjadi contoh untuk atraksinya yang sangat mengaplikasikan budaya Tionghoa, Kampung Korea Bandung akan menjadi contoh untuk konsep sebagai daya tarik yang berada di dalam kawasan CBD atau superblock, sedangkan Santorini Park Cha-Am akan menjadi contoh fasilitasnya. 
Tabel 5. Perbandingan Benchmarking

\begin{tabular}{|c|c|c|c|c|}
\hline \multirow[b]{2}{*}{ Kriteria } & \multicolumn{4}{|c|}{ Objek Studi Sejenis } \\
\hline & $\begin{array}{l}\text { Kampung } \\
\text { Korea } \\
\text { Bandung }\end{array}$ & $\begin{array}{l}\text { Chinatown } \\
\text { Bandung }\end{array}$ & $\begin{array}{l}\text { Santorini } \\
\text { Park Cha- } \\
\text { Am }\end{array}$ & $\begin{array}{l}\text { Objek } \\
\text { Studi }\end{array}$ \\
\hline Karakter bangunan yang khas & $\sqrt{ }$ & $\sqrt{ }$ & $\sqrt{ }$ & $\sqrt{ }$ \\
\hline $\begin{array}{l}\text { Menggunakan gaya bangunan yang unik } \\
\text { sebagai daya tarik utama }\end{array}$ & $\sqrt{ }$ & $\sqrt{ }$ & $\sqrt{ }$ & $\sqrt{ }$ \\
\hline $\begin{array}{l}\text { Terdapat landmark berupa patung, pintu } \\
\text { gerbang, kuil dan bangunan arsitektural } \\
\text { lainnya }\end{array}$ & $\sqrt{ }$ & $\sqrt{ }$ & $\sqrt{ }$ & $\sqrt{ }$ \\
\hline $\begin{array}{l}\text { Masyarakat berperan dalam memasarkan } \\
\text { dan mempromosikan produk }\end{array}$ & $\sqrt{ }$ & $\sqrt{ }$ & & $\sqrt{ }$ \\
\hline Adanya aktivitas belanja di dalam kawasan & $\sqrt{ }$ & $\sqrt{ }$ & $\sqrt{ }$ & $\sqrt{ }$ \\
\hline $\begin{array}{l}\text { Adanya kegiatan yang dilakukan pada hari- } \\
\text { hari besar }\end{array}$ & & $\sqrt{ }$ & & $\sqrt{ }$ \\
\hline $\begin{array}{l}\text { Memiliki pertunjukkan atraksi budaya yang } \\
\text { bertujuan sebagai edukasi bagi pengunjung }\end{array}$ & $\sqrt{ }$ & $\sqrt{ }$ & & $\sqrt{ }$ \\
\hline $\begin{array}{l}\text { Merupakan wisata buatan manusia berbasis } \\
\text { budaya }\end{array}$ & $\sqrt{ }$ & & & $\sqrt{ }$ \\
\hline $\begin{array}{l}\text { Lokasi merupakan bagian dari CBD/ } \\
\text { superblock }\end{array}$ & $\sqrt{ }$ & & & $\sqrt{ }$ \\
\hline Lokasi di kawasan yang mudah dijangkau & $\sqrt{ }$ & $\sqrt{ }$ & & $\sqrt{ }$ \\
\hline Persentase Kemiripan dengan Objek Studi & $90 \%$ & $80 \%$ & $40 \%$ & $100 \%$ \\
\hline
\end{tabular}

Sumber: Penulis, 2019

Berdasarkan perbandingannya Kampung Korea Bandung memiliki kemiripan dengan objek studi, sehingga dalam melakukan pengembangan untuk objek studi akan lebih condong mengarah kepada Kampung Korea Bandung. Setelah melalui analisis objek studi sejenis maka, berikut adalah ruang-ruang yang akan ditambah di Kampung Cina berdasarkan dari analisis objek studi sejenis.

1) Area Makanan dan Minuman

Area makanan dan minuman baik berupa foodcourt, café \& restoran dibutuhkan karena hampir seluruh objek studi sejenis memiliki area makanan dan minuman selain itu juga dikarenakan untuk mendukung kelancaran kegiatan pengunjung dibutuhkan makanan berat untuk mengisi tenaga sehingga area makanan dan minuman dibutuhkan agar para pengunjung tidak perlu lagi keluar masuk kawasan untuk membeli makan.

2) Tempat Kegiatan

Tempat kegiatan untuk rekreasi menjadi sangat penting karena sebuah kawasan wisata harus juga memberikan hiburan bagi para pengunjungnya. Dari rata-rata objek studi sejenis seluruhnya hampir memberikan suguhan wisata yang menarik di dalamnya seperti museum, spot-spot foto, panggung acara, area bermain anak serta taman, sehingga dibutuhkan pula ruang yang difungsikan sebagai tempat-tempat tersebut.

3) Pusat Informasi \& Loket

Pusat informasi dan loket dibutuhkan karena hampir seluruh objek studi memiliki pusat informasi dan loket. Pusat informasi dibutuhkan untuk membantu para pengunjung mendapatkan informasi mengenai hal-hal penting, sedangkan loket dibutuhkan untuk penyediaan dan penjualan tiket masuk objek wisata. Sehingga dibutuhkan pula ruang yang difungsikan sebagai pusat informasi untuk menjadi media dalam mendapatkan informasiinformasi penting baik mengenai objek studi maupun sekitar objek studi serta loket untuk mencegah adanya pungutan liar. 


\section{Analisis Pasar}

Dari hasil analisis pasar didapatkan, berdasarkan responden yang merepresentasikan pengunjung di Kampung Cina terdapat beberapa fasilitas yang perlu dibenahi dan ditambah seperti warung makan, musholla, pos penjaga dan toilet serta terdapat beberapa fasilitas serta atraksi-atraksi yang perlu dihadirkan di dalam Kampung Cina untuk meningkatkan daya tarik pengunjung yang datang. Sedangkan dari pihak pengelola berdasarkan in depth interview mempunyai rencana pengembangan untuk Kampung Cina dengan konsep pengembangan seperti Chinatown Bandung dengan menghadirkan berbagai area spot menarik yang membuat pengunjung tidak bosan untuk berlama-lama di Kampung Cina serta menghadirkan berbagai makanan Cina dan khas Sunda. Dalam upaya melakukan pengembangan terdapat 3 (tiga) alternatif pengembangan yaitu dengan buyback, bagi hasil dan land consolidation namun berdasarkan wawancara dengan pemilik semua pemilik kios memilih strategi buyback, sehingga dapat disimpulkan pemilik kios yang ada di Kampung Cina memilih strategi buyback dengan harga yang dipilih adalah harga appraisal dengan kisaran harga Rp146.000.000 Rp517.000.000. Berdasarkan perhitungan dengan menggunakan penilaian (scoring) pasca pengembangan Kampung Cina akan ditetapkan harga tiket masuk sebesar Rp30.332, namun ada kemungkinan perbedaan harga yang terjadi antara waktu weekdays dan weekend.

\section{Analisis Kebutuhan Ruang}

Analisis kebutuhan ruang dilakukan, tujuannya untuk mengetahui kebutuhan ruang yang akan dibangun berdasarkan analisis sebelumnya. Ruang yang akan dibangun adalah fasilitas dan prasarana pariwisata yang akan menunjang kegiatan wisata di Kampung Cina.

Tabel 6. Kebutuhan Ruang di Kampung Cina

\begin{tabular}{|c|c|c|c|}
\hline Fasilitas & Pengguna & Aktivitas & Kebutuhan Ruang \\
\hline \multirow{5}{*}{$\begin{array}{l}\text { Fasilitas umum } \\
\text { dan fasilitas } \\
\text { pariwisata } \\
\text { untuk kegiatan } \\
\text { atraksi wisata. }\end{array}$} & $\begin{array}{l}\text { Pengunjung yang ingin } \\
\text { menikmati wisata di } \\
\text { Kampung Cina, bermain, } \\
\text { belanja dan berfoto-foto } \\
\text { atau sewa kostum } \\
\text { Cheongsam di Kampung } \\
\text { Cina. }\end{array}$ & $\begin{array}{l}\text { Datang, Bersantai dan } \\
\text { Berbincang, Menikmati } \\
\text { suasana Kampung Cina } \\
\text { (jalan-jalan dan foto- } \\
\text { foto), Istirahat (ibadah } \\
\text { dan makan), Belanja dan } \\
\text { Pulang. }\end{array}$ & $\begin{array}{l}\text { Gazebo, Spot Foto, } \\
\text { Musholla, Tempat Makan, } \\
\text { Wahana bermain anak, } \\
\text { Shop. }\end{array}$ \\
\hline & $\begin{array}{l}\text { Pengunjung yang ingin } \\
\text { menikmati pertunjukkan } \\
\text { barongsai, wushu dan } \\
\text { live music. }\end{array}$ & $\begin{array}{l}\text { Datang, Menikmati } \\
\text { pertunjukkan, Istirahat } \\
\text { (ibadah dan makan) dan } \\
\text { Pulang. }\end{array}$ & $\begin{array}{l}\text { Panggung Acara, Taman, } \\
\text { Musholla dan Tempat } \\
\text { Makan. }\end{array}$ \\
\hline & $\begin{array}{l}\text { Kuliner dan Seni Budaya } \\
\text { Cina. }\end{array}$ & $\begin{array}{l}\text { Datang, Mengenal dan } \\
\text { belajar seni budaya Cina, } \\
\text { Menikmati Kuliner, } \\
\text { Istirahat (ibadah dan } \\
\text { makan) dan Pulang }\end{array}$ & $\begin{array}{l}\text { Museum, Musholla dan } \\
\text { Tempat Makan. }\end{array}$ \\
\hline & $\begin{array}{l}\text { Loket dan Pusat } \\
\text { Informasi Wisata. }\end{array}$ & $\begin{array}{l}\text { Penjualan tiket, Promosi } \\
\text { tempat wisata dan } \\
\text { Pelayanan informasi } \\
\text { wisata. }\end{array}$ & $\begin{array}{l}\text { Loket Tiket dan Kantor } \\
\text { Pusat Informasi Wisata. }\end{array}$ \\
\hline & Keamanan & $\begin{array}{l}\text { Memberikan pertolongan } \\
\text { pertama pada wisatawan } \\
\text { dan Melindungi } \\
\text { wisatawan }\end{array}$ & Pos Keamanan. \\
\hline
\end{tabular}

Sumber: Penulis, 2019 
Tabel 7. Programming Kebutuhan Ruang

\begin{tabular}{|c|c|c|c|c|c|c|c|}
\hline No. & Fasilitas & $\begin{array}{c}\text { Jenis } \\
\text { Kegiatan }\end{array}$ & Kategori & $\begin{array}{l}\text { Luas } \\
\left(\mathrm{m}^{2}\right)\end{array}$ & $\begin{array}{c}\text { Jumlah } \\
\text { Unit }\end{array}$ & $\begin{array}{c}\text { Total Luas } \\
\left(\mathrm{m}^{2}\right)\end{array}$ & $\%$ \\
\hline 1. & Loket Tiket & Fasilitas & Rencana & 6 & 2 & 12 & $0,2 \%$ \\
\hline 2. & Pusat Informasi & Fasilitas & Rencana & 16 & 1 & 16 & $0,2 \%$ \\
\hline 3. & Area Bermain Anak & Rekreasi & Rencana & 500 & 1 & 500 & $6,3 \%$ \\
\hline 4. & Panggung Acara & Fasilitas & Rencana & 48 & 1 & 48 & $1,9 \%$ \\
\hline 5. & Spot Foto Indoor & Rekreasi & Rencana & 500 & 1 & 500 & $6,3 \%$ \\
\hline 6. & Studio Kostum & Rekreasi & Rencana & 80 & 1 & 80 & $1 \%$ \\
\hline 7. & Museum & Rekreasi & Rencana & 100 & 1 & 100 & $1,3 \%$ \\
\hline 8. & Foodcourt & Fasilitas & Rencana & 9 & 25 & 225 & $2,8 \%$ \\
\hline 9. & Café \& Restoran & Fasilitas & Rencana & 200 & 9 & 1.800 & $22,5 \%$ \\
\hline 10. & Taman & Fasilitas & Rencana & & & 600 & $7,5 \%$ \\
\hline 11. & Shop & Fasilitas & Rencana & 48 & 24 & 1.152 & $14,4 \%$ \\
\hline 12. & Toilet Pria & Fasilitas & Eksisting & 28,1 & 2 & 56,2 & $0,7 \%$ \\
\hline 13. & Toilet Wanita & Fasilitas & Eksisting & 26,8 & 2 & 53,6 & $0,7 \%$ \\
\hline 14. & Musholla & Fasilitas & Eksisting & 42,5 & 1 & 825 & $1 \%$ \\
\hline 15. & Tempat Wudhu & Fasilitas & Rencana & 20 & 2 & $0<, J$ & $1 \%$ \\
\hline 16. & Gazebo & Fasilitas & Eksisting & 10 & 2 & 20 & $0,3 \%$ \\
\hline 17. & Pos Penjaga & Fasilitas & Eksisting & 12 & 3 & 36 & $0,5 \%$ \\
\hline \multicolumn{6}{|c|}{ Total Luas Pengembangan } & 5.383 & $67 \%$ \\
\hline \multicolumn{6}{|c|}{ Luas Infrastruktur } & 1.720 & $22 \%$ \\
\hline \multicolumn{6}{|c|}{ Total Luas Kampung Cina } & 8.000 & \\
\hline \multicolumn{6}{|c|}{ Total Luas Lahan yang Dimanfaatkan } & 7.103 & $89 \%$ \\
\hline
\end{tabular}

Sumber: Penulis, 2019

Dari perhitungan di atas dapat dilihat bahwa total luas yang akan dimanfaatkan adalah sebesar $89 \%$ dan $11 \%$ sisanya merupakan area eksisting.

\section{Analisis Investasi}

Tabel 8. Cashflow Investasi Buyback

\begin{tabular}{lrr}
\hline Cashflow & Keterangan & \multicolumn{1}{c}{ Total } \\
\hline CASH IN & & $20,000,000,000$ \\
\hline Modal Awal & & $108,706,599,130$ \\
\hline Tiket Masuk Kampung Cina & $10 \%$ dari pendapatan tiket masuk & $10,870,659,913$ \\
\hline Tiket Spot Foto Indoor & & $447,756,260,734$ \\
\hline Sewa Kostum & & $28,985,030,020$ \\
\hline Shop & & $10,859,958,592$ \\
\hline Area Bermain Anak & & $724,163,791$ \\
\hline Foodcourt & & $734,656,013$ \\
\hline Café \& Restoran & & $\mathbf{6 2 8 , 6 3 7 , 3 2 8 , 1 9 3}$ \\
\hline TOTAL CASH IN & & \\
\hline & & $22,400,000,000$ \\
\hline CASH OUT & Pengembalian Pinjaman + Suku Bunga & $63,898,899,500$ \\
\hline Biaya Pengembalian Pinjaman Bank & $6,389,889,950$ \\
\hline Hard Cost & $10 \%$ dari total hard cost & $1,277,977,990$ \\
\hline Biaya Perencanaan & $2 \%$ dari total hard cost & $\mathbf{2 4 3 , 4 5 4 , 9 3 1 , 2 7 7}$ \\
\hline Biaya Pra Operasional & $40 \%$ dari total pendapatan & $6,389,889,950$ \\
\hline Biaya Operasional dan Maintenance & 10\% daritotal hard cost & $31,431,866,410$ \\
\hline Pajak & $5 \%$ dari pendapatan & $\mathbf{3 7 5 , 2 4 3 , 4 5 5 , 0 7 7}$ \\
\hline Biaya Tak Terduga & & $\mathbf{2 5 3 , 3 9 3 , 8 7 3 , 1 1 6}$ \\
\hline TOTAL CASH OUT & &
\end{tabular}

Sumber: Penulis, 2019 
Tabel 9. Kesimpulan Investasi Buyback

\begin{tabular}{lcccc}
\hline \multicolumn{1}{c}{ Skenario } & NPV & IRR & Payback Period & Profitability Index \\
\hline Pesimis & 25.163 .684 .214 & $14 \%$ & Tahun ke-8 & 1,62 \\
\hline Moderat & 39.584 .501 .380 & $18 \%$ & Tahun ke-7 & 1,68 \\
\hline Optimis & 43.585 .252 .767 & $19 \%$ & Tahun ke-7 & 1,69 \\
\hline
\end{tabular}

Sumber: Penulis, 2019

Berdasarkan perhitungan investasi, dapat dilihat bahwa pengembangan Kampung Cina apabila membuyback seluruh kios masih tetap untung dengan payback period dalam jangka waktu 8 tahun. Dalam skenario moderat, IRRnya adalah 18\% dimana dapat dikatakan cukup tinggi dibandingkan dengan suku bunga sehingga bila dilihat dari sisi investasi pengembangan kawasan sudah termasuk investasi yang baik. Profitability index juga cukup tinggi dimana keuntungan yang didapatkan adalah 1,68 kali lebih banyak dibandingkan biaya yang dikeluarkan. Sedangkan untuk skenario optimis, IRR dapat mencapai 19\%, payback period selama 7 tahun dan profitability index 1,69. Dalam perhitungan analisis investasi ini dapat disimpulkan bahwa dari sisi investasi proyek ini dapat dikatakan layak, meskipun profitability index yang masih tinggi tetapi resikonya rendah dengan tingkat pengembalian selama 7 tahun sampai dengan 8 tahun.

Tabel 10. Cashflow Investasi Bagi Hasil

\begin{tabular}{lrr}
\hline Cashflow & Keterangan & \multicolumn{1}{c}{ Total } \\
\hline CASH IN & & \\
\hline Modal Awal & & $20,000,000,000$ \\
\hline Tiket Masuk Kampung Cina & 10\% dari pendapatan tiket masuk & $109,243,913,438$ \\
\hline Tiket Spot Foto Indoor & & $10,924,391,344$ \\
\hline Sewa Kostum & & $447,756,260,734$ \\
\hline Shop & & $56,803,278,230$ \\
\hline Area Bermain Anak & & $10,859,958,592$ \\
\hline Foodcourt & & $754,163,791$ \\
\hline Café \& Restoran & & $754,183,624$ \\
\hline TOTAL CASH IN & & $657,096,149,752$ \\
\hline & & \\
\hline CASH OUT & Pengembalian Pinjaman + Suku Bunga & $22,400,000,000$ \\
\hline Biaya Pengembalian Pinjaman Bank & & $54,000,989,500$ \\
\hline Hard Cost & $10 \%$ dari total hard cost & $5,400,098,950$ \\
\hline Biaya Perencanaan & $2 \%$ dari total hard cost & $1,080,019,790$ \\
\hline Biaya Pra Operasional & $40 \%$ dari total pendapatan & $254,838,459,901$ \\
\hline Biaya Operasional dan Maintenance & $10 \%$ daritotal hard cost & $5,400,098,950$ \\
\hline Pajak & $5 \%$ dari pendapatan & $32,854,807,488$ \\
\hline Biaya Tak Terduga & & $375,974,474,579$ \\
\hline TOTAL CASH OUT & & $281,121,675,174$ \\
\hline & & \\
\hline CASHFLOW & & \\
\hline Sumber:Penus, & & \\
\hline & & \\
\hline
\end{tabular}

Sumber: Penulis, 2019

Tabel 11. Kesimpulan Investasi Bagi Hasil

\begin{tabular}{lcccccc}
\hline \multirow{2}{*}{ Skenario } & \multirow{2}{*}{ NPV } & \multirow{2}{*}{ IRR } & $\begin{array}{c}\text { Payback } \\
\text { Period }\end{array}$ & $\begin{array}{c}\text { Profitability } \\
\text { Index }\end{array}$ & \multicolumn{2}{c}{ Bagi Hasil } \\
\cline { 5 - 7 } & & & $\mathbf{1 2} \mathbf{~ m}^{\mathbf{2}}$ & $\mathbf{1 5} \mathbf{~ m}^{\mathbf{2}}$ \\
\hline Pesimis & 33.679 .290 .453 & $19 \%$ & Tahun ke-7 & 1,67 & 156.996 .162 & 196.245 .202 \\
\hline Moderat & 55.402 .526 .768 & $25 \%$ & Tahun ke-6 & 1,75 & 190.931 .340 & 238.664 .176 \\
\hline Optimis & 82.872 .822 .472 & $33 \%$ & Tahun ke-5 & 1,82 & 233.244 .747 & 291.555 .934 \\
\hline
\end{tabular}

Sumber: Penulis, 2019 
Berdasarkan perhitungan investasi, dapat dilihat bahwa pengembangan Kampung Cina dengan skenario bagi hasil, masih tetap untung. Dalam skenario moderat, IRRnya adalah $25 \%$ dengan profitability index juga cukup tinggi dimana keuntungan yang didapatkan adalah 1,75 kali lebih banyak dibandingkan biaya yang dikeluarkan. Sedangkan untuk skenario optimis, IRR dapat mencapai 33\%, payback period selama 5 tahun dan profitability index 1,82 . Dalam perhitungan analisis investasi ini dapat disimpulkan bahwa dari sisi investasi proyek ini dapat dikatakan layak, meskipun investasi buyback dan bagi hasil memiliki untung yang besar tetapi resikonya tinggi dikarenakan IRR yang cukup besar.

Tabel 12. Cashflow Investasi Land Consolidation

\begin{tabular}{|c|c|c|}
\hline Cashflow & Keterangan & Total \\
\hline \multicolumn{3}{|l|}{ CASH IN } \\
\hline Modal Awal & & $20,000,000,000$ \\
\hline Tiket Masuk Kampung Cina & & $110,426,532,792$ \\
\hline Tiket Spot Foto Indoor & $10 \%$ dari pendapatan tiket masuk & $11,042,653,279$ \\
\hline Sewa Kostum & & $447,756,260,734$ \\
\hline Area Bermain Anak & & $10,859,958,592$ \\
\hline Foodcourt & & $754,163,791$ \\
\hline Café \& Restoran & & $723,997,239$ \\
\hline TOTAL CASH IN & & $601,563,566,427$ \\
\hline \multicolumn{3}{|l|}{ CASH OUT } \\
\hline Biaya Pengembalian Pinjaman Bank & Pengembalian Pinjaman + Suku Bunga & $22,400,000,000$ \\
\hline Hard Cost & & $57,461,399,500$ \\
\hline Biaya Perencanaan & $10 \%$ dari total hard cost & $5,746,139,950$ \\
\hline Biaya Pra Operasional & $2 \%$ dari total hard cost & $1,149,227,990$ \\
\hline Biaya Operasional dan Maintenance & $40 \%$ dari total pendapatan & $232,625,426,571$ \\
\hline Pajak & $10 \%$ daritotal hard cost & $5,746,139,950$ \\
\hline Biaya Tak Terduga & $5 \%$ dari pendapatan & $30,078,178,321$ \\
\hline TOTAL CASH OUT & & $355,206,512,282$ \\
\hline CASHFLOW & & $246,357,054,145$ \\
\hline
\end{tabular}

Sumber: Penulis, 2019

Tabel 13. Kesimpulan Investasi Land Consolidation

\begin{tabular}{lcccc}
\hline \multicolumn{1}{c}{ Skenario } & NPV & IRR & Payback Period & Profitability Index \\
\hline Pesimis & 26.316 .479 .313 & $16 \%$ & Tahun ke-7 & 1,63 \\
\hline Moderat & 42.014 .251 .681 & $20 \%$ & Tahun ke-7 & 1,69 \\
\hline Optimis & 44.890 .691 .059 & $21 \%$ & Tahun ke-6 & 1,70 \\
\hline
\end{tabular}

Sumber: Penulis, 2019

Berdasarkan perhitungan investasi, dengan skenario buyback dan land consolidation dapat dilihat bahwa pengembangan Kampung Cina apabila melakukan land consolidation masih tetap untung dengan payback period dalam jangka waktu 7 tahun. Dalam skenario moderat, IRRnya adalah $20 \%$ dimana dapat dikatakan cukup tinggi dibandingkan dengan suku bunga sehingga bila dilihat dari sisi investasi pengembangan kawasan sudah termasuk investasi yang baik. Profitability index juga cukup tinggi dimana keuntungan yang didapatkan adalah 1,69 kali lebih banyak dibandingkan biaya yang dikeluarkan. Sedangkan untuk skenario optimis, IRR dapat mencapai 21\%, payback period selama 6 tahun dan profitability index 1,70. Dalam perhitungan analisis investasi buyback - land consolidation dapat disimpulkan bahwa dari sisi investasi proyek ini dapat dikatakan layak dan beresiko rendah dengan tingkat pengembalian selama 6 tahun sampai dengan 7 tahun. 
Kesimpulan dari segi investasi, wisata ini dinyatakan layak baik dari skenario buyback keseluruhan kios, skenario buyback dan bagi hasil serta buyback dan land consolidation, namum pada skenario buyback - bagi hasil IRR dan profitability index yang dihasilkan cukup tinggi yang berarti mendapatkan untung yang besar dalam waktu 5 tahun sampai dengan 7 tahun tetapi memiliki resiko yang besar. Sedangkan pada skenario buyback keseluruhan kios dan buybackland consolidation IRR dan profitability index yang dihasilkan kecil sehingga resikonya kecil untuk dilakukan pengembangan karena memenuhi persyaratan analisis finansial dengan waktu pengembalian 6 tahun sampai dengan 8 tahun. Sehingga dari kesuluruhan skenario dapat disimpulkan skenario yang baik untuk dijadikan acuan dalam pengembangan adalah skenario buyback - land consolidation dikarenakan tingkat resiko yang rendah dan payback period 6 tahun -7 tahun.

\section{KESIMPULAN}

Kampung Cina merupakan tempat wisata yang memiliki potensi baik untuk dikembangan. Hal ini dikarenakan lokasinya yang mudah dicapai dari Jakarta, Depok, Tangerang, Bekasi dan lain-lain dan masih terdapat angkutan umum yang melewati meskipun jumlahnya sedikit dan perlu dilanjutkan dengan ojek atau transportasi online. Pada Kampung Cina dibutuhkan perbaikan dan penambahan beberapa fasilitas untuk dapat memenuhi kebutuhan dan memberikan kenyamanan bagi pengunjung, terdapat beberapa aspek yang dapat ditiru dan diaplikasikan di Kampung Cina, yaitu konsep kawasan wisata di dalam area superblock dari Kampung Korea Bandung, atraksi dan konsep kawasan objek wisata dari Chinatown Bandung dan fasilitas dari Santorini Park Cha-Am.

Dalam melakukan pengembangan di Kampung Cina terdapat 3 (tiga) alternatif pengembangan yaitu, buyback seluruh kios, bagi hasil dan land consolidation dengan harga buyback yang dilakukan berdasarkan harga appraisal adalah Rp146.000.000 - Rp517.000.000. Dari segi investasi, wisata ini dinyatakan layak dengan dijadikan acuan dalam pengembangan adalah skenario buyback dan land consolidation dikarenakan tingkat resiko yang rendah dan payback period 6 tahun -8 tahun.

\section{DAFTAR PUSTAKA}

Baund B., Manuel, \& Lawson F. (1998). Tourism and recreaction development: a handbook of physical planning. Boston: CBI Publisher.

Pemerintah Indonesia. (2009). Undang-Undang Republik Indonesia Nomor 10 Tahun 2009 tentang Kepariwisataan. Lembaran RI Tahun 2009 No. 10. Jakarta: Sekretariat Negara.

Philips, R. (2008). An introduction to community development routledge. British: Routledge.

Sefira R. P., Mardiyono, Riyanto. (2013). Analisis strategi pengembangan pariwisata daerah: studi pada dinas kebudayaan dan pariwisata daerah kabupaten nganjuk. Jurnal Administrasi Publik, 1(4), 135-143.

Spillane, James. J. (1987). Pariwisata indonesia, sejarah dan prospeknya. Yogyakarta: Kanisius.

Spillane, James. J. (1994). Pariwisata indonesia: siasat ekonomi dan rekayasa kebudayaan. Yogyakarta: Kanisius.

Swantoro, G. (1997). Dasar-dasar pariwisata. Yogyakarta: Penerbit ANDI.

Swarbrooke, J. (1996). Pengembangan pariwisata. Jakarta: Gramedia Pustaka Utama.

Yahya, M. (2017). Strategi pengembangan permandian wisata ompo sebagai daya tarik wisata alam di kabupaten soppeng. Jurnal Kepariwisataan, 1(2), 88-98

Yoeti, O. A. (1996). Pengantar ilmu pariwisata. Bandung: Angkasa.

Zalukhu, S. dan Koen M. (2009). Panduan dasar pelaksanaan ekowisata. Jakarta: UNESCO Office. 